\title{
0 ensino da disciplina de projeto arquitetônico auxiliado pela realidade aumentada
}

\author{
The teaching of the discipline of architectural design aided by \\ augmented reality
}

\section{La enseñanza de la disciplina del diseño arquitectónico con la ayuda de la realidad aumentada}

Jonathan Felipe da Silva ${ }^{1}$; Jefferson Queiroz Lima ${ }^{1}$; Sandro César Silveira Jucá ${ }^{1}$; Adriano Bayma de Mesquita ${ }^{1}$; Aldayr de Oliveira Monteiro ${ }^{1}$

\section{RESUMO}

Os recursos tecnológicos são cada dia mais adotados dentro da escola, substituindo as tradicionais lousas. Os projetores multimídias, como exemplo, trazem consigo uma facilidade de apresentação de elementos textuais e de vídeos, potencializando, assim, o campo de ensino e aprendizagem na instituição escolar. O objetivo deste artigo é abordar o uso da tecnologia conhecida como Realidade Aumentada (RA) para que a instrução da disciplina de projeto arquitetônico seja construída de forma mais eficiente. Tal proposta visa sanar uma dificuldade coletiva de visualização tridimensional de elementos arquitetônicos representados em projeto bidimensional. A metodologia utilizada está caracterizada como qualitativa, e também como exploratória e descritiva, por meio de um experimento com uma edificação tridimensional e seu projeto arquitetônico com alunos do Curso Técnico em Edificações ofertado pelo Instituto Federal de Educação, Ciência e Tecnologia do Ceará (IFCE) campus Morada Nova. Tal pesquisa foi aprovada pelo Comitê de Ética e Pesquisa do próprio IFCE, um órgão colegiado interdisciplinar e independente em sua atuação e decisões de sua competência. Os resultados obtidos através da utilização indicam que o uso da RA incrementa a aprendizagem nesta área, sendo necessário apenas o uso de um smartphone com configurações simples e com acesso à internet, para que seja viável a aplicabilidade da RA.

Palavras-chave: Ensino-aprendizagem; Projeto arquitetônico; Realidade aumentada.

\begin{abstract}
ABSTRACT

Technological resources are increasingly adopted within the school, replacing traditional slates. Multimedia projectors, as an example, bring with them an easy presentation of textual elements and videos, thus enhancing the teaching and learning field in the school institution. The purpose of this article is to address the use of technology known as Augmented Reality (AR) so that the instruction of the architectural design discipline is built more efficiently. This proposal aims to remedy a collective difficulty in visualizing three-dimensional architectural elements represented in two-dimensional design. The methodology used is characterized as qualitative, as well as exploratory and descriptive, through an experiment with a three-dimensional building and its architectural project with students of the Technical Course in Buildings offered by the Federal Institute of Education, Science and Technology of Ceará (IFCE) Morada Nova campus. Such research was approved by the Ethics and Research Committee of IFCE itself, an interdisciplinary collegiate body and independent in its performance and decisions within its competence. The results obtained through the use indicate that the use of $A R$ increases learning in this area, requiring only the use of a smartphone with simple configurations and internet access, so that the applicability of $A R$ is viable.
\end{abstract}

Keywords: Teaching-learning; Architectural project; Augmented reality.

\footnotetext{
${ }^{1}$ IFCE - Instituto Federal do Ceará/CE - Brasil.
} 


\section{RESUMEN}

Los recursos tecnológicos se adoptan cada vez más dentro de la escuela, reemplazando las pizarras tradicionales. Los proyectores multimedia, como ejemplo, traen consigo una presentación fácil de elementos textuales y videos, mejorando así el campo de enseñanza y aprendizaje en la institución escolar. El propósito de este artículo es abordar el uso de la tecnología conocida como Realidad Aumentada (AR) para que la instrucción de la disciplina del diseño arquitectónico se construya de manera más eficiente. Esta propuesta tiene como objetivo remediar una dificultad colectiva en la visualización de elementos arquitectónicos tridimensionales representados en un diseño bidimensional. La metodología utilizada se caracteriza como cualitativa, además de exploratoria y descriptiva, a través de un experimento con un edificio tridimensional y su proyecto arquitectónico con estudiantes del Curso Técnico en Edificaciones que ofrece el Instituto Federal de Educación, Ciencia y Tecnología de Ceará (IFCE). Campus Morada Nova. Dicha investigación fue aprobada por el propio Comité de Ética e Investigación de la IFCE, órgano colegiado interdisciplinario e independiente en su desempeño y decisiones dentro de su competencia. Los resultados obtenidos a través del uso indican que el uso de la RA aumenta el aprendizaje en esta área, requiriendo solo el uso de un teléfono inteligente con configuraciones simples y acceso a internet, para que la aplicabilidad de la RA sea viable.

Palabras clave: enseñanza-aprendizaje; Proyecto arquitectónico; Realidad aumentada.

\section{INTRODUÇÃO}

O projeto arquitetônico representa um produto fundamental para a construção de uma edificação. Materializa as ideias e conceitos acordados entre o projetista e o(s) futuro(s) usuário(s) do espaço construído nas definições do programa de necessidades², acabamentos, localização, entre outros. É caracterizado como a base para os outros projetos complementares, tais como projeto estrutural, hidrossanitário, paisagístico, entre outros.

Desta forma, é imprescindível que o aluno compreenda os fundamentos e as normas, além de desenvolver a sua habilidade de visualização tridimensional, para que o projeto arquitetônico seja melhor construído, resultando em uma edificação bem resolvida em relação aos fluxos, ao layout ${ }^{3}$ e também em relação aos materiais empregados.

A disciplina de Projeto Arquitetônico, ministrada principalmente nos cursos de graduação em Arquitetura e Urbanismo e nos cursos de Tecnólogo e de Técnico em Edificações, assume este papel fundamental para a futura profissão do estudante, uma vez que o torna capaz de compreender o conjunto arquitetônico e também de executar os desenhos técnicos obedecendo as normas vigentes.

Diante dos desafios encontrados para que seja efetivada a construção do conhecimento, se encontra a dificuldade por parte da maioria dos alunos em visualizar de forma abstrata o conjunto tridimensional do edifício. Esta dificuldade está presente em ambos os cursos referidos anteriormente, uma vez que quase a totalidade dos alunos não desenvolveu esta habilidade ao longo do ensino fundamental e ensino médio, não se apropriando de forma prévia da capacidade de manusear o projeto arquitetônico executado no plano bidimensional e logo abstraí-lo de forma tridimensional em sua mente.

Zevi (1994) aborda sobre esta questão da discrepância de entendimento entre a indicação do espaço arquitetônico e a sua compreensão real, tanto em relação à largura e profundidade, quanto em relação à escala, uma vez que, no projeto, estão indicadas representações abstratas.

\footnotetext{
2 Síntese das necessidades dos clientes, representadas por uma lista com os espaços e áreas totais definidas.

${ }^{3}$ Organização interna dos ambientes da edificação.
} 
Para sanar esta questão, buscou-se no presente artigo trabalhar utilizando a ferramenta da RA para incentivar o aluno a desenvolver esta capacidade de abstração, uma vez que, através desta, é possível analisar os projetos impressos em conjunto com seu modelo tridimensional, de forma concomitante, apenas com a utilização de um smartphone com acesso à internet.

Apesar de não representar uma tecnologia nova, datada da década de 1960, a RA ainda não é amplamente utilizada em sala de aula. Entre os motivos, encontra-se a ausência de formação do professor sobre a ferramenta. Há diversos textos sobre a eficiência da RA no ensino de projeto, como Sá (2007), que analisa o decréscimo de erros construtivos, ao se planejar a edificação utilizando recursos da RA. Ainda, segundo Kumaran; Santhi; Anand (2007), é apresentado o desenvolvimento, entre outros, de projetos de interiores e restauração de edifícios com o auxílio da RA.

A partir deste entendimento, buscou-se a aplicação da RA com alunos do curso Técnico em Edificações ofertado pelo IFCE campus Morada Nova, através de um aplicativo de RA disponível gratuitamente, conhecido como Augin ${ }^{\circledR 4}$, objetivando para a visualização de um edifício de forma tridimensional, unido ao seu projeto arquitetônico impresso. Os alunos, desta forma, poderão compreender este aspecto de forma mais ampla, reduzindo os riscos de falha de comunicação e de compatibilização entre os projetos.

\section{METODOLOGIA}

A pesquisa se caracteriza como qualitativa, e também como exploratória e descritiva, uma vez que buscou-se realizar um levantamento de um experimento de RA com alunos do curso Técnico em Edificações ofertado pelo IFCE campus Morada Nova, por meio do desenho de um projeto arquitetônico de uma edificação fictícia através do software AutoCAD ${ }^{\circledR}$, realizando a sua modelagem tridimensional de uma edificação por meio do programa SketchUP ${ }^{\circledR}$ e, posteriormente, a sua configuração para ser exibida em RA através do software gratuito denominado Augin ${ }^{\circledR}$.

Utilizou-se, na pesquisa, a consulta a livros e artigos sobre o tema da RA e sobre suas aplicações didáticas. Em relação aos autores com obras textuais sobre a RA, foram analisados: Tori e Hounsell (2018) e também os autores Tori, Kirner e Sicouto (2006), Azuma (2001) e ainda Thornton; Ernst; Clark (2012), onde puderam ser identificados as propriedades relacionadas à RA e à Realidade Virtual (RV).

Realizou-se, ainda, pesquisas sobre a utilização da RA na Educação, ao consultar os artigos produzidos pelos autores Lopes, Vidotto, Pozzebom, Ferenhof (2019), Silva (2018) e Zorzal, Jorge, Costa (2018).

Além disso, buscou-se, com as produções dos autores Sá (2007), Kumaran; Santhi; Anand (2007), Araújo (2018), Moreira, Ruschel (2015) e Terra, Augusto (2019) as relações entre a RA e o ensino de projeto, abordando sobre a grande possibilidade de sucesso ao aplicar esta tecnologia em sala de aula.

Ao construir esta base teórica, foi realizada a aplicação da RA com os alunos através do programa Augin $^{\circledR}$, que além do site próprio, constitui-se de um aplicativo gratuito para fins de interação com

\footnotetext{
${ }^{4}$ Disponível em <https://augin.app/> Acesso em setembro 2020.
} 
modelos tridimensionais. Este mesmo aplicativo é capaz de gerar um marcador de RA, sendo este processo descrito detalhadamente na seção intitulada aplicação da pesquisa, resultados e discussão.

\title{
3. REFERENCIAL TEÓRICO
}

Esta seção realiza uma explanação sobre as principais características da RA e suas distinções em relação à RV. Além disso, apresenta um estudo sobre a importância da tecnologia dentro do processo de ensino-aprendizagem da disciplina de Projeto Arquitetônico.

\subsection{A RA e suas características}

A evolução de forma acelerada das tecnologias de informação e comunicação (TICs) tornou viável a utilização de novos instrumentos didáticos por meio de mecanismos tecnológicos. Um dispositivo já utilizado em algumas indústrias e em treinamentos, sendo também eficaz em sala de aula, seria a RA. Segundo Thornton; Ernst; Clark (2012), a RA é:

\begin{abstract}
Uma tecnologia emergente que implica ser forte como uma ferramenta de aprendizagem na implementação de currículos de educação tecnológica. Há potencial para RA a ser incorporados em não somente a ciência, tecnologia, Engenharia e educação matemática, mas em todas as disciplinas. RA pode auxiliar no projeto, permitindo aos alunos construir objetos interativos, criar modelos visuais para acompanhar problemas de matemática, examinar os problemas de Engenharia a partir de múltiplas perspectivas. (THORNTON; ERNST; CLARK, p. 4, 2012).
\end{abstract}

Desta forma, esta ferramenta se apresenta como um importante auxílio para diversos objetivos, entre eles, a potencialização do processo ensino-aprendizagem. De acordo com Tori, Kirner e Siscouto (2006, p.25), uma outra definição para RA seria "[...] o enriquecimento do ambiente real com objetos virtuais, usando algum dispositivo tecnológico, funcionando em tempo real." Portanto, segundo Azuma (2001), a RA representa a inserção de dados virtuais dentro de elementos reais, onde estão relacionados de forma interativa, para que o usuário possa compreender de uma forma mais completa a sua realidade.

Além disso, o ambiente que prevalece é o real, sendo o universo virtual apresentado como um complemento. Ainda segundo Azuma (2001), um conjunto de RA possui três características: combinar os objetos reais e os virtuais dentro do ambiente real; ser interativo e em tempo real; alinhar os objetos virtuais e reais entre si, no mesmo plano. Seguindo estes conceitos, a Figura 1 expõe o uso da RA inserida na área da construção civil:

Figura 1: Exemplo de aplicação de RA

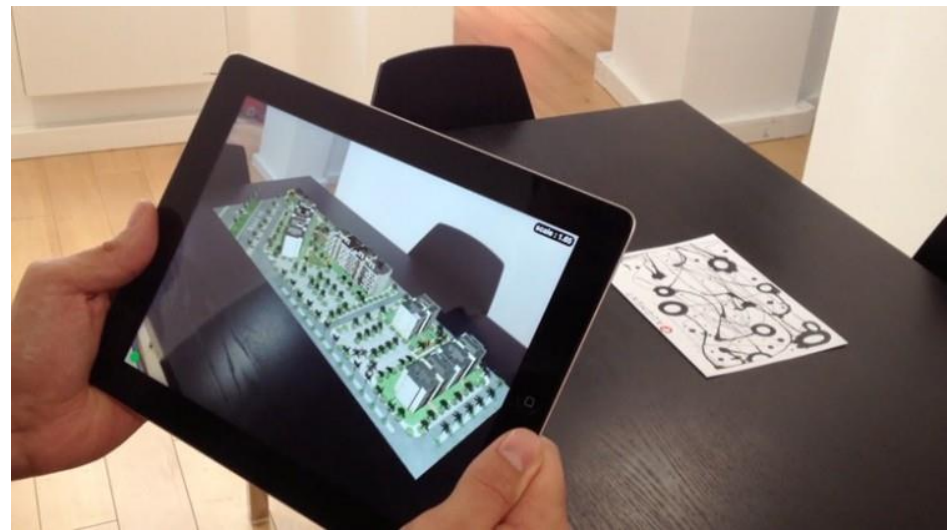

Fonte: Recuperado em 10 set 2020 de https://www.hometeka.com.br/pro/realidade-aumentada-emarquitetura-o-que-achamos-do-app-augment/ 
Quando ocorre o oposto, o universo virtual assume a função primordial se comparado com o real, neste caso se caracteriza como RV. Erroneamente considerados conceitos semelhantes, a RV (com um exemplo de aplicação indicado na Figura 3) tem a capacidade de ilusão dos sentidos do usuário, uma vez que o transporta para um ambiente primordialmente virtual com efeitos visuais, sonoros e, em alguns casos, táteis. O detalhe está na observação que esta realidade existe independentemente da interação do próprio usuário. Esta diferença entre RA e RV está especificada na Figura 2, que demonstra o diagrama das artificialidades e espaços:

Figura 2: Diagrama das artificialidades e espaços

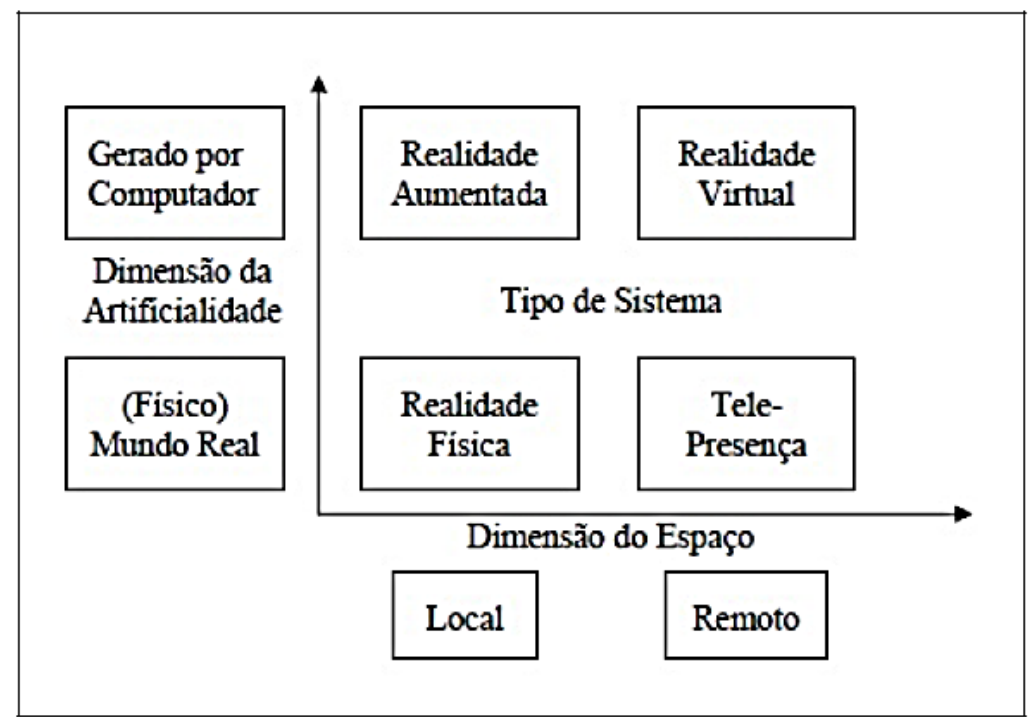

Fonte: Benford (1998)

Figura 3: Aplicação da RV

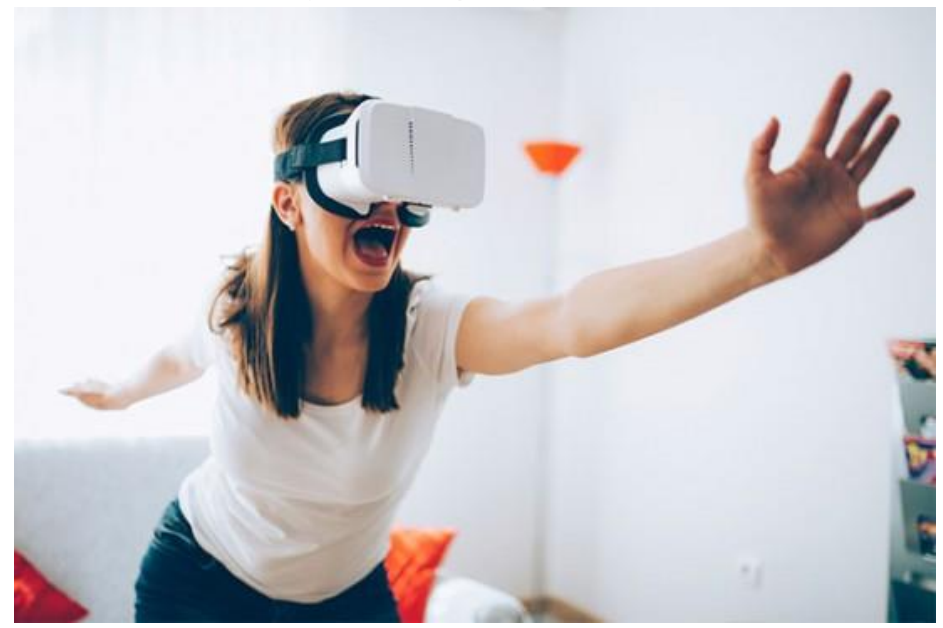

Fonte: Recuperado em 10 set 2020 de https://blogs.correiobraziliense.com.br/tecnoveste/realidade-virtual-oque-e-como-funciona-e-para-que-serve-realidade-virtual-realidade-mista/

Na Figura 2 acima, percebe-se que a RA está relacionada com a realidade física (mundo real), e a RV está caracterizada como a tele presença (mundo virtual). A RA necessita de algum apoio de ferramenta tecnológica, para que seja possível realizar a integração com informações virtuais. Já a RV exige um aparato tecnológico maior, uma vez que o usuário será levado para um universo totalmente modificado.

Portanto, segundo Tori e Hounsell (2018), as características principais da RA são:

A. é o enriquecimento do ambiente real com objetos virtuais, usando algum dispositivo tecnológico, funcionando em tempo real (Augment,2017); 
B. é uma melhoria do mundo real com textos, imagens e objetos virtuais, gerados por computador (Insley 2003 apud Kirner e Tori, 2006);

C. é a mistura de mundos reais e virtuais em algum ponto do espectro que conecta ambientes completamente reais a ambientes completamente virtuais (Milgram 1994);

D. é um sistema que suplementa o mundo real com objetos virtuais gerados por computador, parecendo coexistir no mesmo espaço e apresentando as seguintes propriedades (Azuma et al., 2001): combina objetos reais e virtuais no ambiente real; executa interativamente em tempo real; alinha objetos reais e virtuais entre si; aplicase a todos os sentidos, incluindo audição, tato e força e cheiro. (TORI; HOUNSELL p.40, 2018)

Além disso, para que exista o processo em sua totalidade da RA, é necessária a presença de um marcador, que representa uma imagem previamente configurada e reconhecida pela câmera utilizada pelo software de RA. Esta imagem é processada pelo programa e, em seguida, é desenvolvido o elemento tridimensional interativo. Os marcadores podem ser representados por imagens dos mais diversos tamanhos e cores, além de, em alguns casos, representarem o próprio ambiente onde estaria localizado o objeto tridimensional. A Figura 4 traz um exemplo de um marcador padrão de RA:

Figura 4: Exemplo de um marcador de RA

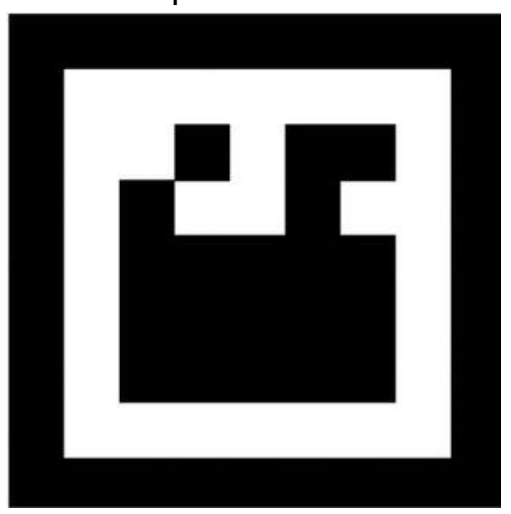

Fonte: Recuperado em 11 set 2020 de https://www.researchgate.net/figure/Figura-12-Marcador-2D-umexemplo-de-um-marcador-2D_fig9_308657938

No campo da Construção Civil, a RA tem sido utilizada como um simulador para localizar, entre outros, a estrutura e as instalações nas alvenarias, além de um guia para a construção de elementos. Apesar de ainda não ser facilmente encontrada no mercado da construção civil, apresenta diversos benefícios, tais como uma redução de tempo e de recursos, uma vez que o funcionário terá em suas mãos orientações práticas de como executar o serviço e como será o resultado final. As Figuras 5 e 6 ilustram algumas aplicações atuais desta tecnologia em obras do campo da construção civil:

Figura 5: exemplo de aplicação da RA dentro de uma construção

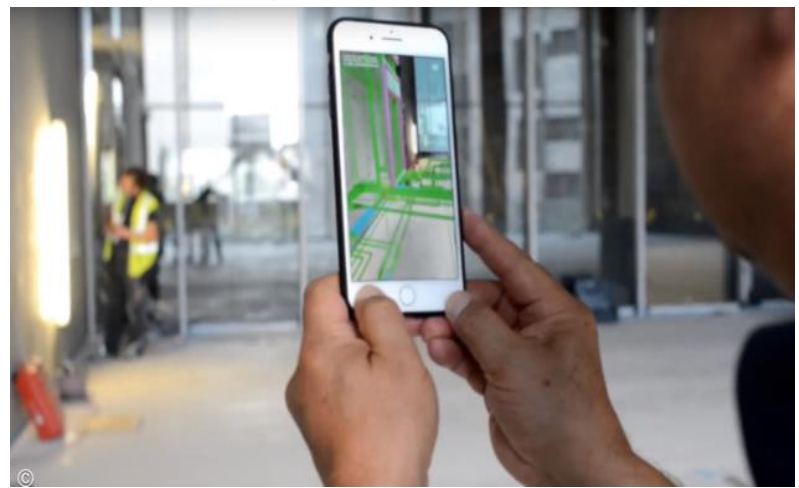

Fonte: Recuperado em 10 set 2020 de https://www.archdaily.com.br/br/914441/8-tecnologias-de-realidadeaumentada-para-construcao 
Figura 6: exemplo de aplicação da RA dentro de uma construção

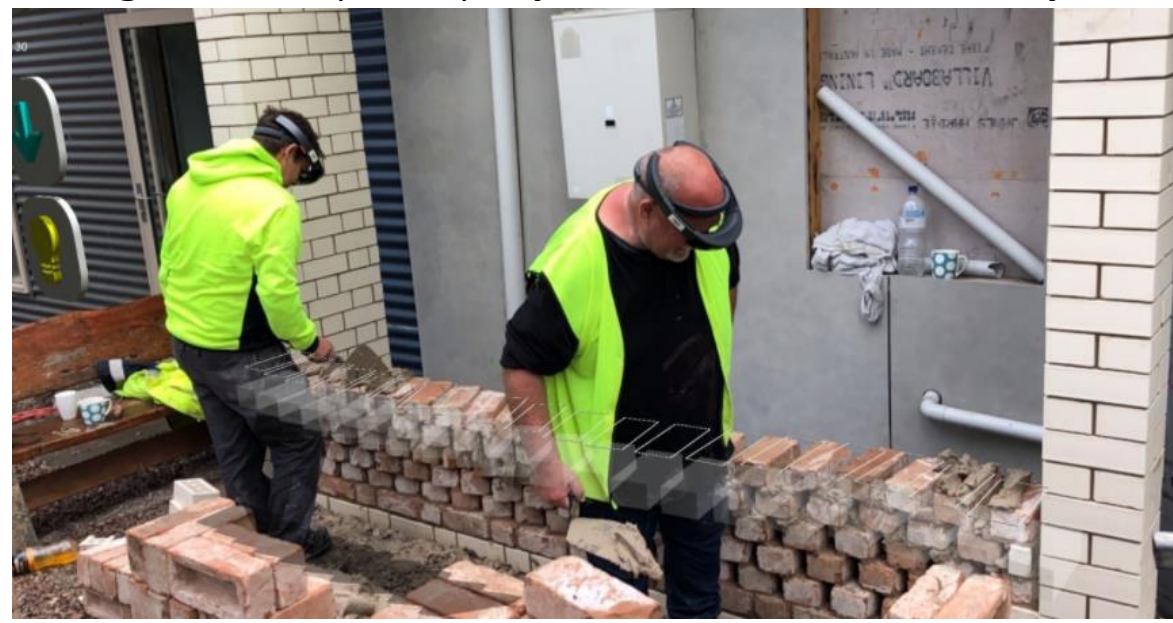

Fonte: Recuperado em 10 set 2020 de https://www.archdaily.com.br/br/914441/8-tecnologias-de-realidadeaumentada-para-construcao/5ca63f64284dd1e433000076-8-tecnologias-de-realidade-aumentada-paraconstrucao-foto

\subsection{A Tecnologia e o Processo Ensino-Aprendizagem de Projeto Arquitetônico}

Conforme Morán (2015, p. 15), "a educação formal encontra-se em um enorme dilema, pois necessita se transformar para continuar relevante e ainda fazer com que os alunos obtenham uma formação humana, social e profissional". Portanto, é importante que o professor atualize a sua metodologia, inserindo novas tecnologias. A utilização dos recursos tecnológicos, segundo Bueno (1999, p.87) descreve que esta tecnologia deve ser:

[...] um processo contínuo através do qual a humanidade molda, modifica e gera a sua qualidade de vida. Há uma constante necessidade do ser humano de criar, a sua capacidade de interagir com a natureza, produzindo instrumentos desde os mais primitivos até os mais modernos, utilizando-se de um conhecimento cientifico para aplicar a técnica e modificar, melhorar, aprimorar os produtos oriundo do processo de interação deste com a natureza e com os demais seres humanos (BUENO, 1999, p. 87).

Desta forma, é perfeitamente possível a associação dos recursos tecnológicos no ambiente educacional, motivando os alunos para a discussão dos temas propostos. Segundo Gabriel (2013):

Quando uma revolução tecnológica acontece, ela recria a realidade e transforma o impossível em possível. Antes do século XX, voar era impossível para o ser humano, bem como um indivíduo trabalhar em uma cidade e morar em outra, porém, hoje essas são coisas comuns. Há dez anos apenas, era impossível assistir vídeos no celular, e hoje isso é usual. Assim, o que realmente importa em uma revolução tecnológica não é a tecnologia em si, mas o que fazemos com ela e como ela pode melhorar as nossas vidas (GABRIEL, 2013, cap. 7).

Lopes, Vidotto, Pozzebom, Ferenhof (2019) indicam que é possível a aplicação da RA em jogos como um ótimo instrumento de aprendizagem. Além disso, Silva (2018) afirma que uma possibilidade de utilização da RA na escola seria por meio do laboratório de informática ou um outro espaço semelhante, sempre com o apoio principal do docente. É necessário que o ambiente escolar esteja devidamente preparado para receber esta tecnologia, para que o desenvolvimento dos alunos ocorra de forma integrada e potencializada.

De acordo com Zorzal, Jorge, Costa (2018), há uma abordagem sobre a utilização da RA em especial nas disciplinas de história e biologia, e ainda há uma clara percepção da melhoria de aprendizado por 
parte dos discentes quando se insere a ferramenta da RA dentro do contexto construído para o ensino destas disciplinas.

Considerando a teoria da Aprendizagem Significativa de David Ausubel, o autor Silva (2020) afirma que tal teoria abrange o conhecimento prévio como o fator que mais influencia a aprendizagem dos alunos, embora este seja apenas um dos fatores necessários, já que necessita também da predisposição do aluno para aprender e de material de ensino potencialmente significativo.

Ao realizar uma análise desta teoria relacionada aos conceitos e aplicações da RA, percebe-se que esta tem um grande potencial de significar a aprendizagem dos alunos, uma vez que o discente, na posse de seu conhecimento prévio sobre a disciplina ministrada, é capaz de desenvolver o aprendizado de forma mais intensa, pois é motivado por esta tecnologia e pelo material de apoio, que pode ser acessado pelo seu próprio smartphone ou tablet.

Trazendo a discussão para o campo da disciplina de projeto arquitetônico, em qualquer curso, é exigida uma metodologia específica para que esta seja desenvolvida de forma eficaz. A começar pela mesa de trabalho do aluno, que não deve ser a tradicional carteira, com um braço lateral ou uma pequena mesa, mas uma mesa de desenho com tamanho padrão, além da recomendada existência de uma régua paralela fixada na própria mesa, como descrito na Figura 7:

Figura 7: Modelo da mesa para o desenvolvimento de desenho de projetos arquitetônicos

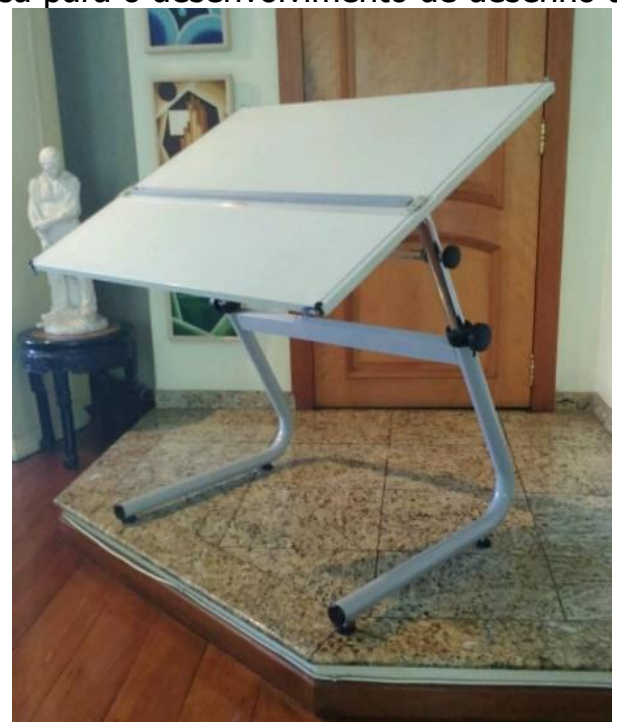

Fonte: Recuperado em 11 set 2020 de https://br.pinterest.com/pin/568227677963591960/

Assim, será possível a construção dos projetos através das normas aplicadas ao desenho técnico ${ }^{5}$. Ainda, a própria estrutura e layout da sala de aula apresentam características distintas de uma sala de aula tradicional. Em uma disciplina de Projeto Arquitetônico, o professor necessita transitar de forma constante entre as mesas de desenho, a verificar o andamento das atividades, não se encontrando restrito à frente do quadro branco, por exemplo. Além disso, o aluno necessita de um espaço maior para armazenar seus equipamentos de desenho e também um espaço para transitar entre as mesas dos alunos vizinhos, como forma de construção de projetos colaborativos. A Figura 8 traz um exemplo de uma organização de sala de aula para o desenvolvimento das aulas de projeto arquitetônico:

\footnotetext{
${ }^{5}$ Um campo do desenho, onde é regido por regras de normalização técnica, além de conceitos da Geometria Descritiva, Perspectivas, Escalas entre outros.
} 
Figura 8: Sala de aula da disciplina de projeto da Faculdade de Arquitetura e Urbanismo da Universidade de São Paulo (FAU/USP)

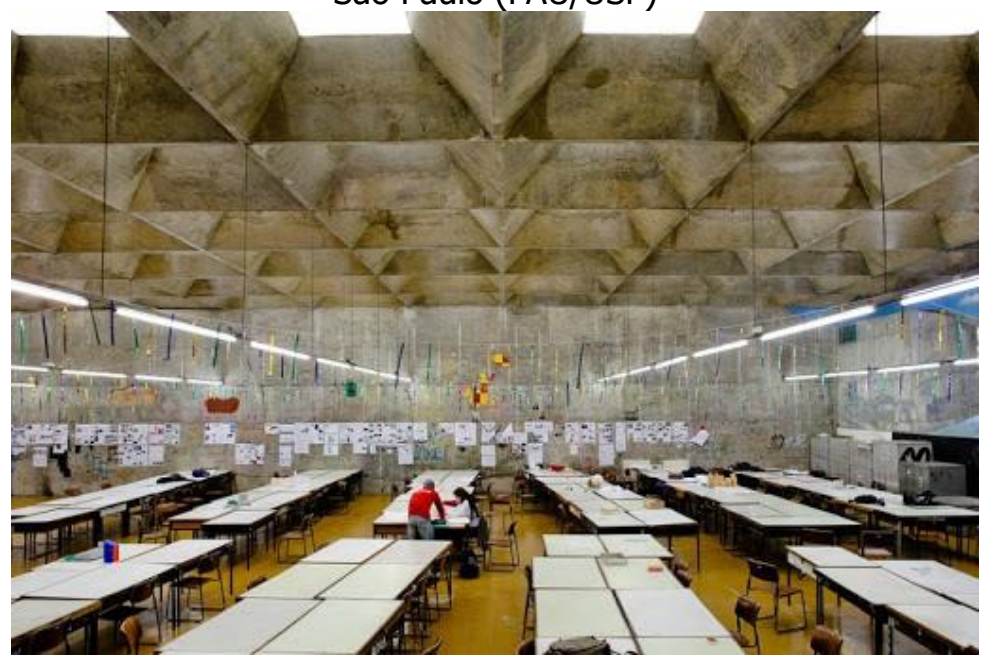

Fonte: Recuperado em 10 set 2020 de http://www.fau.usp.br/author/webfau/

Uma outra particularidade da disciplina de projeto arquitetônico se encontra na possibilidade de ser realizada de forma computadorizada, através de um programa de AutoCAD ${ }^{\circledR} 6$, por exemplo. Neste caso, a organização da sala de aula e as mesas assumiriam uma outra forma de organização e de estrutura. Os alunos teriam acesso a um computador ou estariam em posse de seu próprio notebook com o programa instalado, e serão capazes de operá-lo para a produção dos projetos, sendo supervisionado pelo professor.

Portanto, ao relatar esta realidade das aulas de projeto arquitetônico, percebe-se que tanto o professor quanto o aluno devem se adaptar a esta forma específica de ensino, a começar pela utilização ampla da tecnologia em sala de aula. Segundo Demo (2008):

Temos que cuidar do professor, pois todas as mudanças só entram bem na escola se entrarem pelo professor, ele é a figura fundamental. Não há como substituir o professor. Ele é a tecnologia das tecnologias, e deve se portar como tal. (Apud ANDRADE, p.16)

Segundo Cortella (2014, p.59) "em maior ou menor escala, a tecnologia invadiu a sala de aula. Mas isso não significa necessariamente que o desafio do professor tenha mudado". Por isso, é designado ao professor a iniciativa da utilização da tecnologia em sala de aula. Não é diferente quando se trata da disciplina de projeto arquitetônico, pois o discente necessita conhecer as ferramentas tecnológicas para a produção de projetos, uma vez que o mercado de trabalho já a utiliza de forma ampla, reservando a um pequeno grupo de trabalho os projetos realizados totalmente à mão, com o auxílio de instrumentos de desenho.

Mesmo com o domínio de todas estas ferramentas tecnológicas e dos instrumentos de desenho, o aluno muitas vezes ainda possui a dificuldade da visualização de forma abstrata do edifício em plano tridimensional. O professor necessita, desta forma, incentivar o uso de recursos que expõem de forma interativa esta visualização. 0 que se percebe é que muitas vezes o docente não consegue potencializar este conhecimento apenas com o uso da lousa, quadro branco ou mesmo os atuais programas de modelagem virtual de edifícios. É necessário que o aluno observe, de forma

\footnotetext{
${ }^{6}$ Abreviação de Computer Aided Design, representa um programa bastante usual de desenho auxiliado por computador, para a elaboração de desenhos técnicos, com versão educacional disponível de forma gratuita, mediante prévio cadastro.
} 
concomitante, o projeto no plano bidimensional e que esta visualização seja sobreposta ao seu plano tridimensional.

Ao observar a planta baixa, por exemplo, o discente precisa compreender os elementos ali presentes em sua forma integral, para que seja potencializado o seu entendimento espacial e também a capacidade de sugerir melhorias para o edifício. Este talvez seja o principal desafio para que 0 processo de ensino-aprendizagem da disciplina de projeto arquitetônico seja efetivado de forma plena. Assim, para a compreensão das regras do desenho técnico e das formas de utilização das ferramentas e dos programas, o aluno obtém sucesso com mais facilidade do que desenvolver a sua própria visão espacial.

O primeiro passo para alcançar este objetivo, seria realizar alterações no currículo do curso. Segundo Silva (2001, p.14-15), há uma indagação sobre como devem estar organizados os processos organizacionais e relacionados ao ensino para que possa demonstrar a sua verdadeira essência e identidade de conhecimentos. Assim, as disciplinas presentes nos currículos devem preparar de forma completa o futuro profissional. Deve haver a potencialização da tecnologia dentro da sala de aula, para que o aluno possa interagir com os recursos disponíveis e atingir seus objetivos didáticos. Como afirmam Mendonça e Mustaro (2011):

[...] A Realidade Aumentada em Educação pode constituir um elemento motivador, bem como despertar a atenção do estudante. (MENDONÇA; MUSTARO, p. 101, 2011).

Seguindo nesta temática, a RA se apresenta como uma excelente ferramenta tecnológica e de baixo custo de aplicação para superar muitos desafios impostos a este processo de ensino-aprendizagem. O discente teria a oportunidade de visualizar na tela do smartphone ou do computador a edificação de forma tridimensional, além de interagir com ela de forma dinâmica, observando os elementos arquitetônicos representados anteriormente apenas de forma bidimensional.

Segundo Araújo (2018), como a RA possui uma infinidade de possibilidades, tais como na área de construção civil e em treinamentos, existem diversos meios de aplica-la dentro do processo de ensino. Moreira e Ruschel (2015) afirmam que tanto a RV quanto a RA são consideradas tecnologias de grande relevância para os arquitetos e urbanistas quando se trata da visualização do projeto final. Terra e Augusto (2019) reconhecem que existe um mercado em pleno crescimento onde o profissional formado com o auxílio da RA pode obter um maior êxito, uma vez que terá um aprendizado mais eficaz na área de projeto.

Relacionando a teoria da Aprendizagem Significativa de David Ausubel abordada anteriormente com o ensino de projeto arquitetônico, percebe-se que o aluno estaria notadamente mais incentivado a realizar as atividades em sala de aula, já que, através de seu conhecimento prévio sobre conceitos de projeto arquitetônico, tem a possibilidade de praticar e consolidar tais conceitos utilizando o seu aparelho celular.

Portando, o professor teria uma facilidade maior em fazer-se compreender ao longo das aulas de projeto arquitetônico, e teria um maior incentivo por parte do aluno durante o desenvolvimento das atividades projetuais. 


\section{APLICAÇÃO DA PESQUISA, RESULTADOS E DISCUSSÃO}

Como discutida nas seções anteriores, a tecnologia da RA se apresenta como uma aliada ao processo de aprendizado, devendo ser incorporada aos currículos dos cursos tanto de graduação quanto aqueles de nível fundamental e médio. Por representar uma tecnologia de baixo custo, é possível esta aplicação para fins didáticos. É preciso, anteriormente, uma preparação do docente, para que possa trabalhar de forma correta com os alunos dentro do tema da RA, e para que possa extrair os melhores resultados de aprendizado.

Seguindo esta premissa, foi desenvolvido o conceito da RA aplicado ao aprendizado de projeto arquitetônico. Para que se torne possível o desenvolvimento deste trabalho, inicialmente foi desenvolvido com os alunos do Curso Técnico em Edificações do IFCE campus Morada Nova um modelo de edificação tridimensional e o seu projeto arquitetônico bidimensional. $O$ modelo bidimensional foi construído no software AutoCAD ${ }^{\circledR}$, enquanto o modelo tridimensional foi projetado por meio do software SketchUP ${ }^{\circledR} 7$.

Assim, dentro do programa AutoCAD ${ }^{\circledR}$, desenvolveram-se os projetos das fachadas da edificação através de uma planta baixa pré-definida. Foi possível, assim, visualizar o projeto de forma bidimensional. Posteriormente, foi construído o modelo tridimensional deste edifício, através do programa SketchUP ${ }^{\circledR}$, com duração de 5 horas para a confecção. E em seguida, foi exportado para um software de elementos interativos, conhecido como Augin ${ }^{\circledR}$, onde foi configurado para ser visualizado através da RA, por meio de um marcador. A seguir, será descrito de forma detalhada o passo a passo da pesquisa de utilização da RA para a potencialização do ensino aprendizado de projeto arquitetônico.

Como descrito nos parágrafos anteriores, o primeiro procedimento realizado foi a construção do projeto arquitetônico através do software AutoCAD ${ }^{\circledR}$ versão educacional. Foi desenvolvido com os alunos o projeto de uma casa com área de 62,06 metros quadrados, em apenas 1 (um) pavimento. Esta edificação representa uma residência ainda fictícia, não possuindo nenhuma restrição de direitos autorais, uma vez que foi desenvolvida pelos próprios autores. Tal projeto é demonstrado na Figura 9:

Figura 9: Desenvolvimento do Projeto Arquitetônico da edificação no programa AutoCAD ${ }^{\circledR}$ versão educacional



Fonte: Elaboração própria, 2020.

\footnotetext{
7 Programa pertencente a empresa Trimble Navigation para a criação de modelos tridimensionais, com versões educacionais gratuitas.
} 
Posteriormente, os projetos elaborados foram organizados por assunto, a fim de um melhor entendimento: planta baixa, planta de cobertura e fachadas. Organizando desta forma, o professor, em sala de aula, é capaz de descrever as propriedades de cada tipo de projeto, com sua simbologia de acordo com as normas da Associação Brasileira de Normas Técnicas (ABNT). As Figuras 10, 11 e 12 ilustram os projetos organizados de formas separadas:

Figura 10: Planta baixa desenvolvida no programa $A u t o C A D^{\circledR}$ versão educacional

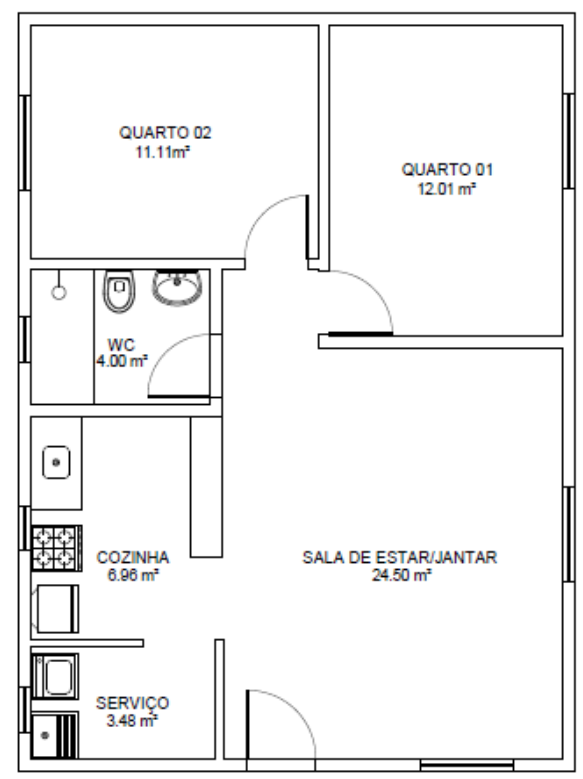

Fonte: Elaboração própria, 2020.

Figura 11: Planta de cobertura desenvolvida no programa AutoCAD ${ }^{\circledR}$ versão educacional

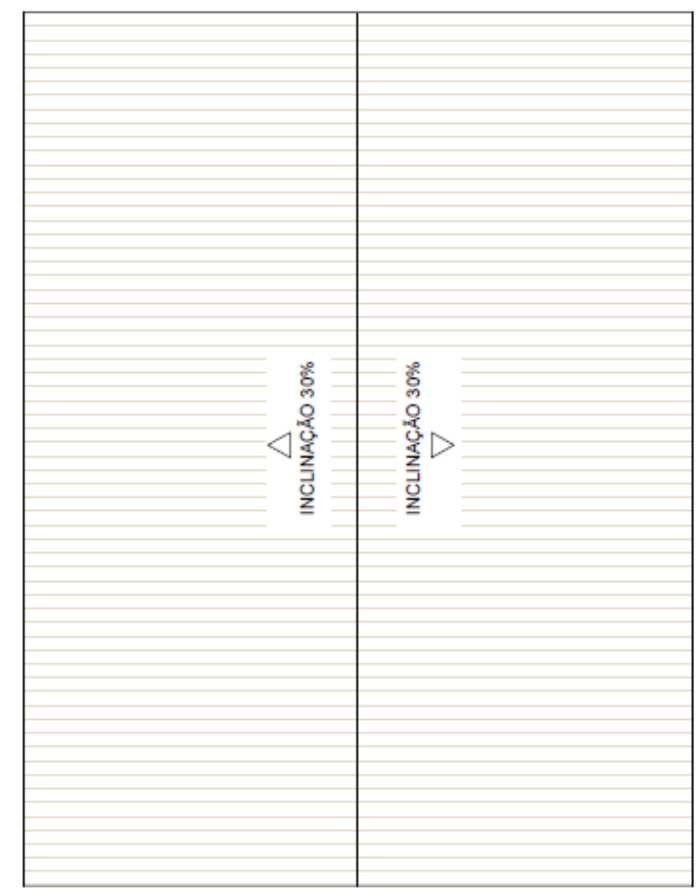

Fonte: Elaboração própria, 2020. 
Figura 12: Plantas de fachadas desenvolvidas no programa AutoCAD ${ }^{\circledR}$ versão educacional
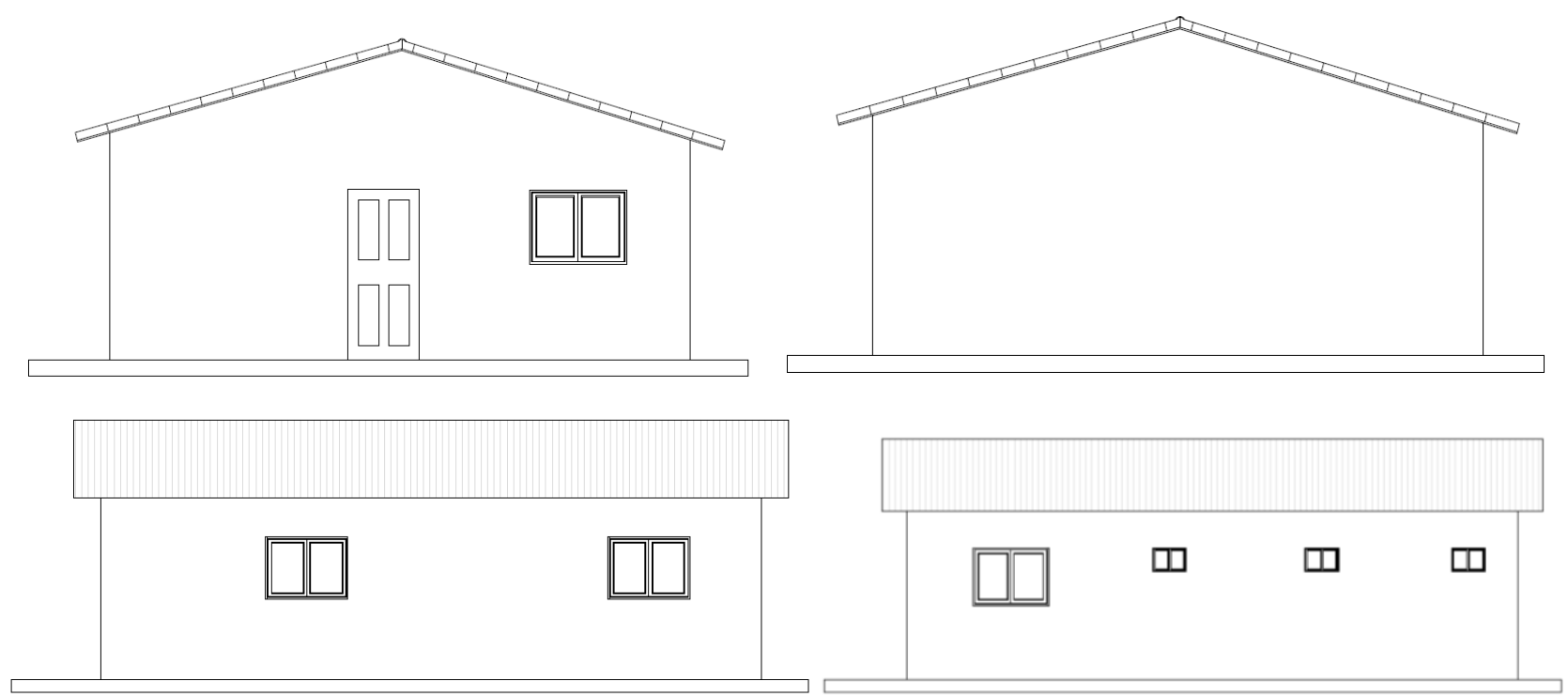

Fonte: Elaboração própria, 2020.

Após concluída a elaboração do projeto arquitetônico no plano bidimensional, os autores e os alunos iniciaram a construção do seu modelo tridimensional, através do software SketchUP ${ }^{\circledR}$ versão educacional (indicada na Figura 13). Tal programa permite que seja realizada a modelagem da edificação dentro da escala previamente definida, com todas as medidas indicadas exatamente como no projeto em AutoCAD ${ }^{\circledR}$. Desta forma, o projeto se torna mais acessível para o entendimento dos próprios alunos em sala de aula.

Figura 13: Modelagem da edificação no programa SketchUP ${ }^{\circledR}$ versão educacional

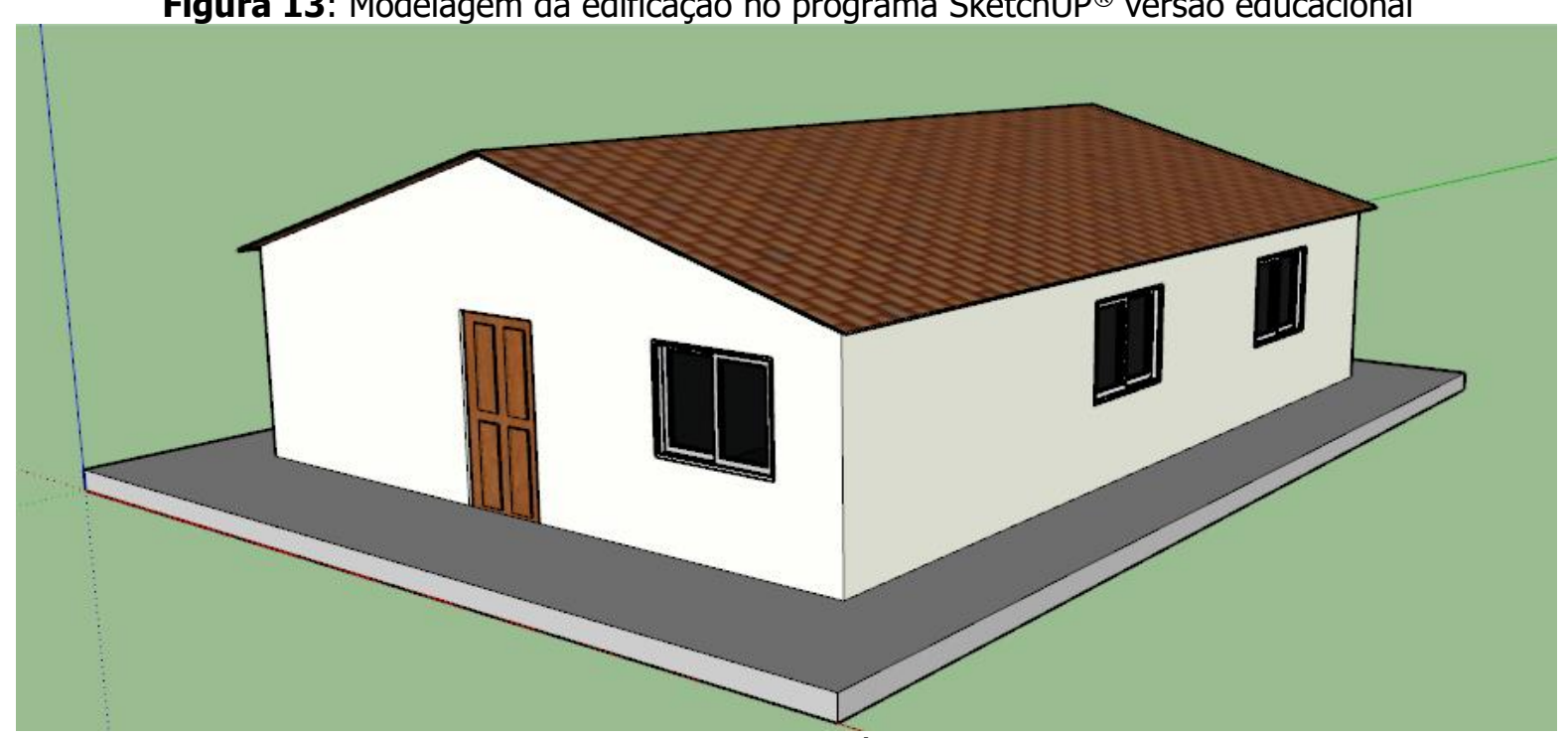

Fonte: Elaboração própria, 2020.

Logo em seguida à modelagem tridimensional, o projeto foi exportado para o site Augin ${ }^{\circledR}$, onde, com o auxílio de um marcador padronizado (Figura 14), foi possível a visualização da edificação em RA com os discentes. 
Figura 14: Marcador definido para a visualização da edificação através da RA

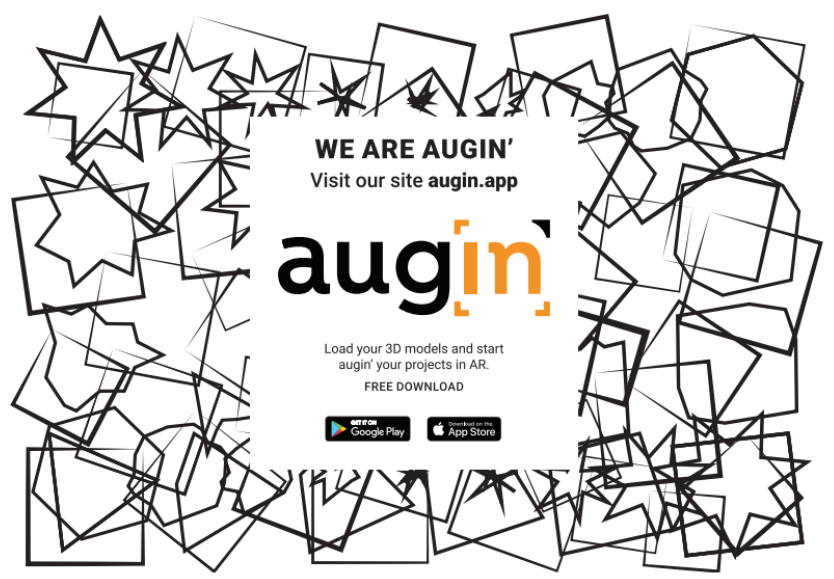

Fonte: Recuperado em 10 set 2020 de https://augin.app/

Posteriormente à configuração do objeto para o marcador, os autores e os alunos se dirigiram para uma bancada de superfície plana e ali foi inserido o marcador impresso em folha de papel tamanho A4. Em seguida, foi instalado em um smartphone com acesso à internet o aplicativo Augin ${ }^{\circledR}$, e logo selecionado o modelo da edificação anteriormente indicado.

Ao selecioná-lo, o programa, através da câmera do smartphone, realizou a leitura do marcador e foi projetado o modelo tridimensional da residência, como exposto nas Figuras 15 e 16:

Figura 15: Visualização da edificação em RA através do aplicativo Augin ${ }^{\circledR}$

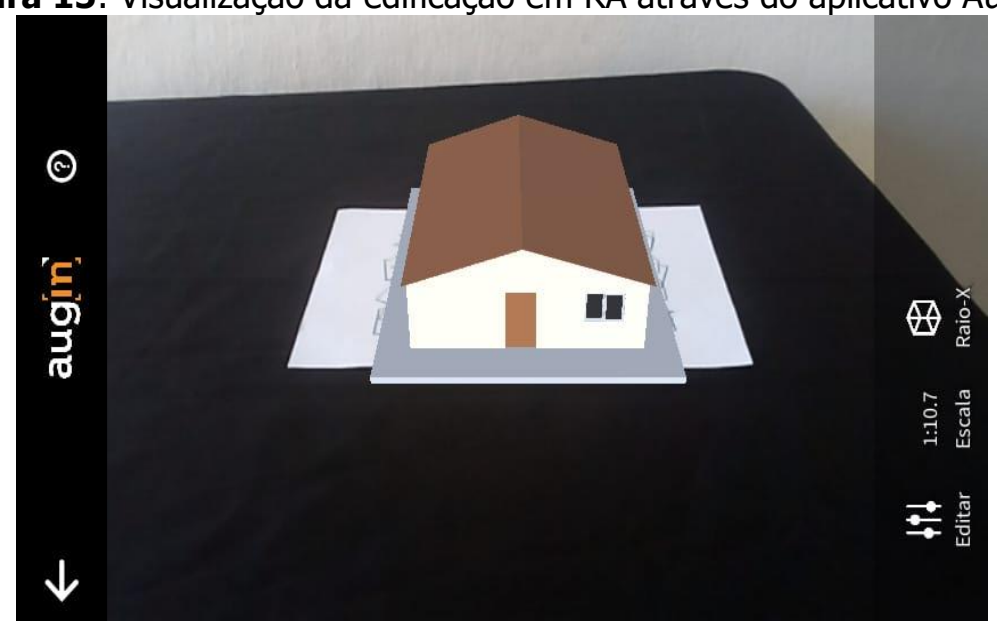

Fonte: Elaboração própria, 2020.

Figura 16: Visualização da edificação em escala no aplicativo Augin ${ }^{\circledR}$ comparada com a escala de uma caneta esferográfica

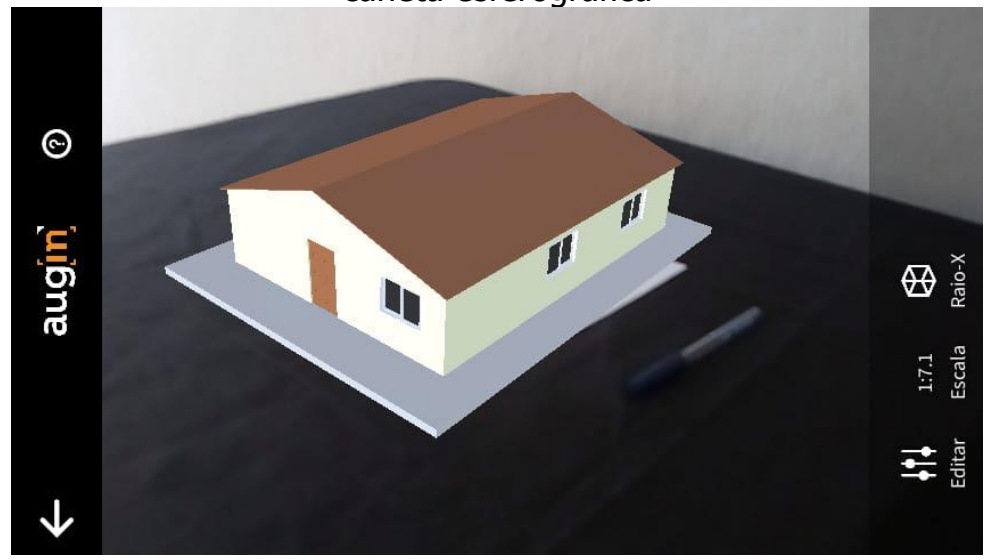

Fonte: Elaboração própria, 2020. 
Quando a edificação é projetada no aplicativo, torna-se possível interagir com o modelo, como realizar rotações, alterações de escala e mesmo a vista do interior, como se o usuário estivesse se deslocando dentro da casa, e visualizando os detalhes do interior da construção. Esta possibilidade traz consigo um grande potencial para o ensino de projeto arquitetônico, pois o aluno seria estimulado a interagir como se o projeto já estivesse materializado, trazendo um conjunto de benefícios para o ensino.

O professor teria uma ferramenta muito importante nas suas aulas da disciplina de projeto arquitetônico, pois o aluno assumiria um papel ativo dentro do processo ensino-aprendizagem. Ele observaria os projetos em AutoCAD ${ }^{\circledR}$, a modelagem tridimensional e a sua projeção em RA, para compreender em sua plenitude o projeto definido.

Os alunos participantes do experimento demonstraram ao final um maior entendimento do conjunto de projetos ao ter a possibilidade de visualizar, ao mesmo tempo, o seu modelo tridimensional. Desta forma, é uma prova concreta que a RA se apresenta como uma grande aliada ao processo de ensino, especificamente nesta pesquisa, de projeto arquitetônico, podendo ser expandida para qualquer outra disciplina ministrada.

\section{CONSIDERAÇÕES FINAIS}

O estudo desenvolvido com os alunos, previamente aprovado pelo Comitê de Ética e Pesquisa do próprio IFCE, demonstrou que a utilização da RA tem um grande potencial de melhoria dos processos de ensino e de aprendizagem para a disciplina de projeto arquitetônico em qualquer curso, uma vez que produz uma grande motivação entre os discentes, trazendo a tecnologia para o seu cotidiano.

Além disso, há uma oportunidade de utilização do próprio smartphone do aluno para fins didáticos. Seria aproveitado o recurso que o discente já possui, sem precisar a escola adquirir bens de tecnologia, uma vez que muitas não possuem esta reserva em seu orçamento. O estudo descreveu que a RA pode ser perfeitamente aplicada com os mínimos de recursos, cabendo ao professor a tomada da iniciativa para trazer esta discussão para a sala de aula.

Este potencial de incentivo à aprendizagem traria uma melhor formação do profissional ou do pesquisador, uma vez que teria acesso a um conjunto de recursos formativos que expandem a sua visão espacial e o seu entendimento sobre a grande área de projeto, não apenas limitando-se à área de projeto arquitetônico.

Nos últimos anos, no Brasil, ainda são percebidas poucas utilizações deste recurso tecnológico em sala de aula, talvez pelos motivos de ausência de conhecimento do professor sobre o tema ou mesmo ausência de uma metodologia específica e aplicável nas escolas e incentivadas pelos gestores. Mas, como descrito por este estudo, a implantação da RA na sala de aula exige poucos recursos, e traria uma grande vantagem para a formação dos estudantes.

Percebe-se que, apesar de não ser considerada uma tecnologia nova, datada da década de 1960, a RA apresenta um enorme potencial de desenvolvimento, com a criação de instrumentos cada vez mais sofisticados. Os alunos certamente se apropriariam deste conhecimento à medida que este for trabalhado em conjunto com o professor. Ainda há diversos desafios a serem superados, porém há, ao mesmo tempo, um grande horizonte de oportunidades para que a RA se torne cada vez mais essencial para o ensino, em especial, de projeto arquitetônico. 


\section{REFERÊNCIAS}

ANDRADE, A. P. R. Uso das tecnologias na educação: computador e internet. 2011. 22 f. Trabalho de Conclusão de Curso (Licenciatura em Biologia) - Universidade Estadual de Goiás, Brasília, 2011. Disponível em:

https://bdm.unb.br/bitstream/10483/1770/1/2011_AnaPaulaRochadeAndrade.pdf. Acesso em: 08/09/2020.

ARAÚJO, Alan Nóbrega Dantas de. Uso de realidade aumentada como auxílio para concepção de projetos arquitetônicos em BIM: experimentos de pesquisa aplicada desenvolvida em disciplinas de modelagem e BIM no curso de Arquitetura e Urbanismo da UFPB entre 2015 e 2017. Universidade Federal da Paraíba. Programa de Pós-Graduação em Arquitetura e Urbanismo. 138p. João Pessoa. 2018. Disponível em:

https://repositorio.ufpb.br/jspui/handle/123456789/13725?locale=pt_BR. Acesso em: 06/11/2020.

AZUMA et al. (2001). Recent advances in augmented reality. IEEE computer graphics and applications, Áustria, v. 21, n. 6, p. 34-47, Nov/Dez. 2001. Disponível em: https://ieeexplore.ieee.org/abstract/document/963459. Acesso em: 08/09/2020.

BUENO, N. O desafio da formação do educador para o ensino fundamental no contexto da educação tecnológica. 1999. 16f. Revista Ibero-americana de Estudos em Educação Universidad de Alcalá, Madri, Espanha, 1999.

CORTELLA, M. S. Educação, escola e docência: Novos tempos, novas atitudes. São Paulo: Cortez, 2014.

DEMO, P. Pedro Demo aborda os desafios da linguagem no século XXI, In: BRASIL. Ministério da Educação. Secretaria de educação à Distância. Tecnologias na Educação: ensinando e aprendendo com as TIC. Brasília: 2008. Disponível em: http://www.nota10.com.br/noticiadetalhe/Pedro-Demo-aborda-os-desafios-da linguagem-no-seculo-XXI. Acesso em: 07/09/2020.

GABRIEL, M. Educ@r - A (r)evolução Digital na Educação. 1. ed. São Paulo: Saraiva, 2013.

KUMARAN, G.; SANTHI, K. R.; ANAND, P. M. Impact of Augmented Reality (AR) in civil engineering. Advanced Materials Research, v. 18-19, Jan/2007. Disponível em:

https://www.researchgate.net/publication/250355839_Impact_of_Augmented_Reality_AR_in_Civil_E ngineering. Acesso em: 08/09/2020.

LOPES, L.M.D.; VIDOTTO, K.N.S.; POZZEBON, E.; H.A. FERENHOF. Inovações Educacionais com o uso da Realidade Aumentada: uma revisão sistemática. EDUR - Educação em revista. 33p. Belo Horizonte. 2019. Disponível em:

https://www.scielo.br/scielo.php?script=sci_arttext\&pid=S010246982019000100403\&tlng=pt. Acesso em: 06/11/2020.

MENDONÇA, R. L.; MUSTARO, P. N. Como tornar aplicações de realidade virtual e aumentada, ambientes virtuais e sistemas de realidade mista mais imersivos. In: SYMPOSIUM ON VIRTUAL AND AUGMENTED REALITY, 13, 2011, Uberlândia/MG. Minas Gerais: SBC, 2011.

MILGRAM, P et al. Augmented Reality: A Class of Displays on the RealityVirtuality Continuum. Society of Photo-optical Instrumentation Engineers, v. 2351, jan/1994. Disponível em: https://www.researchgate.net/publication/228537162_Augmented_reality_A_class_of_displays_on_t he_reality-virtuality_continuum. Acesso em: 10/09/2020.

MORÁN, J. Mudando a educação com metodologias ativas. Convergências Midiáticas, Educação e Cidadania: aproximações jovens. SOUZA, C. A.; MORALES, O. E T (org.). Ponta Grossa: 
UEPG/PROEX, 2015. Disponível em: https://www.ucs.br/site/midia/arquivos/bibliografia-PGCIMAcanela.pdf. Acesso em: 10/09/2020.

MOREIRA, L.; RUSCHEL, R. Realidade aumentada na visualização de soluções do projeto de arquitetura. XIX Congresso da Sociedade Ibero-americana de Gráfica Digital. Florianópolis. 6p. Vol. 2. 2015. Disponível em:

https://www.researchgate.net/publication/285597578_Realidade_Aumentada_na_Visualizacao_de_S olucoes_do_Projeto_de_Arquitetura. Acesso em: 05/11/2020.

SÁ, A et al. Augmented reality to aid construction management. Cmne/Cilamce, n. 13-15, jun/2007. Disponível em:

https://www.researchgate.net/profile/Alberto_Raposo/publication/228612181_Augmented_reality_to _Aid_Construction_Management/links/Ofcfd50bfa77417887000000.pdf. Acesso em: 08/09/2020.

SILVA, Iuri Americano da. O Potencial da Realidade Aumentada na Educação. Congresso Internacional de Educação e Tecnologias - Universidade Federal da Paraíba. 14p. São Carlos. 2018. Disponível em: https://cietenped.ufscar.br/submissao/index.php/2018/article/view/230/249. Acesso em: 05/11/2020.

SILVA, Joao Batista da. A Teoria da Aprendizagem Significativa de David Ausubel: uma análise das condições necessárias. Universidade Estadual do Ceará. Fortaleza. 14p. 2020. Disponível em:

https://www.researchgate.net/publication/339916302_A_Teoria_da_Aprendizagem_Significativa_de _David_Ausubel_uma_analise_das_condicoes_necessarias. Acesso em: 06/11/2020.

SILVA, T. T. Documentos de identidade: uma introdução às teorias do currículo. 2. ed. 2. reimp. Belo Horizonte: Autêntica, 2001.

TERRA, F.B.; AUGUSTO W.F.C. A utilização da realidade virtual e realidade aumentada na representação de projetos arquitetônicos. $19^{\circ}$ Congresso Nacional de Iniciação Científica. 10p. São Paulo. 2019. Disponível em: http://conic-semesp.org.br/anais/files/2019/trabalho1000005050.pdf. Acesso em: 06/11/2020.

THORNTON, T.; ERNST, J. V.; CLARK, A. C. Augmented reality as a visual and spatial learning tool in technology education. Technology \& Engineering Teacher, v. 71, n. 8, p.18-21, Maio/Jun 2012. Disponível em: http://migre.me/dtrE3. Acesso em: 10/09/2020.

TORI, R; KIRNER, C. Fundamentos de realidade virtual. In: TORI, R; KIRNER, C; SISCOUTO, R. (Org). Fundamentos e tecnologia de realidade virtual e aumentada. Porto Alegre: Sociedade Brasileira de Computação, p.9-28. 2006

TORI, R.; HOUNSELL, M. S. (org.). Introdução a Realidade Virtual e Aumentada. Porto Alegre: Editora SBC, 2018. Disponível em: http://www.de.ufpb.br/ labteve/publi/2018_livroRVA.pdf. Acesso em: 10/09/2020.

ZEVI, B. A linguagem Moderna da Arquitetura. Lisboa: Publicações Dom Quixote,1984.

ZORZAL, E. R.; JORGE, J.A.P.; COSTA, G.G. Desafios e aplicações da realidade aumentada móvel na Educação. Revista Renote. UFRGS. V16. 10p. Porto Alegre. 2018. Disponível em: https://seer.ufrgs.br/renote/article/view/89239. Acesso em: 06/11/2020.

Submissão: 28/10/2020

Aceito: 11/11/2020 